\title{
Power Cooling
}

\author{
Erich Opitz ${ }^{1, a^{*}}$, Alois Seilinger ${ }^{1, b}$, Lukas Pichler ${ }^{1, c}$, Olaf Silbermann ${ }^{1, d}$, \\ Axel Rimnac ${ }^{2,}$ e \\ ${ }^{1}$ Rolling Mill Technology, Primetals Technologies $\mathrm{GmbH}$, Linz, Austria \\ ${ }^{2}$ ESP Technology, Primetals Technologies GmbH, Linz, Austria \\ aerich.opitz@primetals.com, balois.seilinger@primetals.com, 9ukas.pichler@primetals.com, \\ dolaf.silbermann@primetals.com, eaxel.rimnac@primetals.com
}

Keywords: Power cooling, late cooling, cooling rates, WISCO, AHSS

\begin{abstract}
During the last years international steel producers have been following a market trend to develop and produce new steel grades with higher strength and larger thickness. When attempting to improve the metallurgical properties in the cooling section, the existing cooling equipment in hot strip mills often reaches its limit. Primetals Technologies offers its Power Cooling solution to upgrade existing cooling lines as well as for new hot strip mills. With this type of equipment highest cooling rates can be achieved and therefore steel producers are capable of producing new steel grades with higher strength at lower costs. A new power cooling system was installed immediately behind the finishing mill gauge house at Wuhan Iron and Steel Company's (WISCO) HSM No. 2 in Wuhan, China. The Power Cooling system widens the product range and gives WISCO the capability to produce high-strength steel grades (AHSS) with strength levels of more than 1,000 MPa, e.g. HSLA steel or as-hot-rolled multi-phase steel. Due to the extremely wide control range of the flow rate, the installation allows for maximum metallurgical flexibility. On the other hand, the new equipment allows for the most economic production of line-pipe material like API X80 in a thickness range up to $25.4 \mathrm{~mm}$ (1 inch).
\end{abstract}

\section{Introduction}

Following market demands currently the general trend is to produce advanced steel grades either with higher strength or larger thickness at reduced costs compared to conventional production. This includes all kinds of AHSS such as DP (Dual-Phase), CP (Complex-Phase), TRIP (Transformation Induced Plasticity), fully-martensitic steels or HSLA grades (e.g. API X70, X80).

Especially when using lean chemistry approaches high cooling rates become important for virtually all advanced steel grades. In order to cover the emerging field of hot rolled multi-phase steels such as TRIP grades, accurate temperature-time path control is needed in a range where the Leidenfrost effect - an insulating steam layer between hot strip surface and cooling water is established - becomes dominant, i.e., fast and homogeneous cooling is of vital interest in the late cooling stage.

In order to account for above mentioned production strategies, one of the appropriate products on the market is the Primetals Power Cooling system. This system has recently been installed at HSM no. 2 of WISCO (Wuhan Iron \& Steel Company). The system is characterized by adjustable cooling rates ranging from moderate cooling rates up to the theoretical limit given by thickness and heat conductivity of the steel strip to be cooled.

Especially late cooling becomes more and more important for producing new steel grades, particularly multi-phase steel, which requires an interrupted cooling strategy combined with sufficiently high cooling rates during the final cooling stage. Rapid cooling of the material ensures better and more uniform metallurgical properties and thus increases the quality of the hot rolled strip. 


\section{Production of Advanced Hot-rolled Steel Grades}

The mechanical properties of hot rolled strips strongly depend on their chemistry and microstructure. The major factors of influence on strength, ductility and toughness of the material are mixed crystal strengthening, grain refinement, content of non-equilibrium phases as well as size and amount of precipitates.

In order to arrive at the desired properties of the final product careful choice of the timetemperature deformation path on the hot strip mill is a must. This includes proper thermomechanical treatment during deformation steps at the roughing and finishing stage as well as the proper cooling strategy at the ROT. Especially for lean chemistries the former usually provides challenges in view of throughput as the requirement of low rolling temperatures for properly pancaked microstructure before transformation and sufficiently high furnace exit temperatures necessary for dissolution of precipitations causes significant constraints for proper pass schedules.

Figure 1 (left) shows schematically the different cooling courses for various types of steel grades produced including the influence of major alloying elements on the $\gamma->\alpha$ phase transformation kinetics. Virtually all important alloying elements delay the transformation from austenite to ferrite, pearlite and non-equilibrium phases. Besides accounting for base strength, to achieve desired amounts of e.g., bainite and martensite in the final product proper alloying with delaying elements or high cooling rates have to be used. An indication on the potential for saving alloying elements in favor of higher cooling rates can be found for example in well calibrated material property simulation tools such as VAI-Q strip (voestalpine) [2] or StripCam (ThyssenKrupp) [3].

Material strengthening by exploiting the Hall-Petch effect, i.e., generation of fine ferrite grain is achieved by applying fast cooling at the early cooling stage. Typically, ferrite grain diameters found after accelerated cooling follow an inverse power law of the cooling rate applied, i.e., the higher the cooling rate the smaller the grain size and, hence, the stronger the matrix. Figure 1 (right) shows the impact of different time-temperature deformation paths on the microstructure of X70 grades.

In order to arrive at the proper microstructure for dual phase (ferrite-martensite) or TRIP-steel (ferrite-(bainite)-residual austenite) one or more holding stages are necessary to generate the necessary amount of ferrite and to account for the proper isothermal-bainite transformation to stabilize the residual austenite in the case of TRIP steels as well as a final quench to the martensite region for dual phase steel. In combination with the finishing mill exit speed the transformation kinetics of the corresponding alloys determine the necessary length of the run-out table.
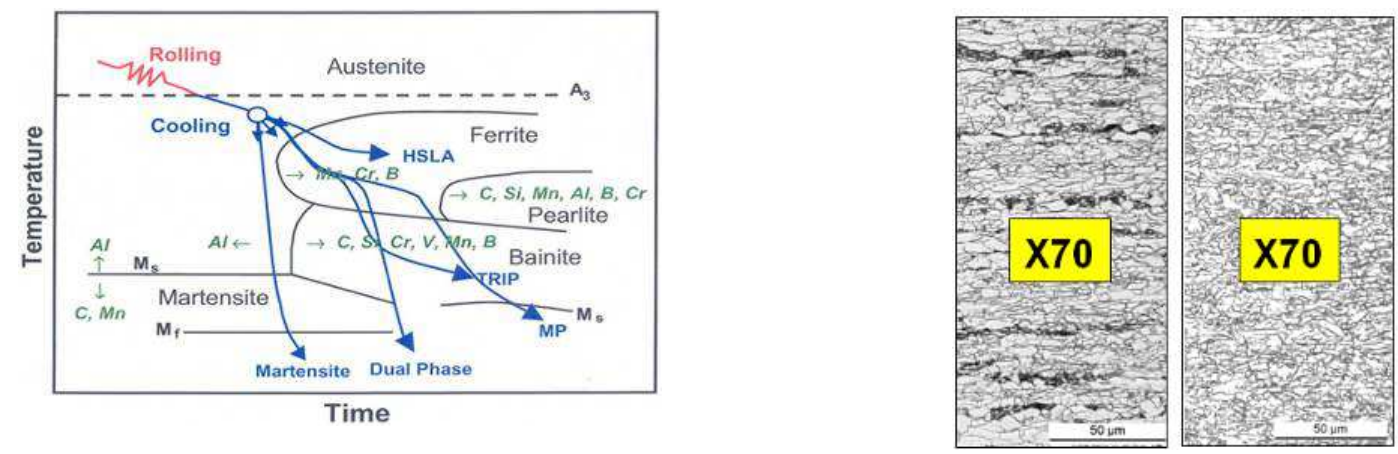

Figure 1 Left: Temperature-time paths for different types of hot-rolled steel grades including HSLA, martensitic steel, dual phase, TRIP and complex/multi-phase grades [5] Right: 2 microstructure of X70 after using different time-temperature-deformation strategies (left: finished rolling temperature (FRT) $\sim 700{ }^{\circ} \mathrm{C}$, air cooling; right: FRT $\sim 850{ }^{\circ} \mathrm{C}+$ accelerated cooling[4]

\section{Primetals Power Cooling - Overview}

Due to its extraordinarily high cooling capacity Power Cooling provides the means to sharply control the microstructural evolution within very short lengths. Depending on the detailed 
requirements given by product mix and layout of a rolling mill several locations for an installation of Power Cooling are identified [1]:

- $\quad$ TBC - Transfer bar cooling

- ISC - Interstand cooling

- EC - "Early cooling" (Pipe grades, HSLA steels, 2 step cooling - AHSS qualities)

- LC - "Late cooling" (2 step cooling, AHSS steel grades - e.g. hot rolled DP, TRIP, Multiphase steel grades)

Furnace Roughing mill Finishing mill Laminar cooling Downcoiler

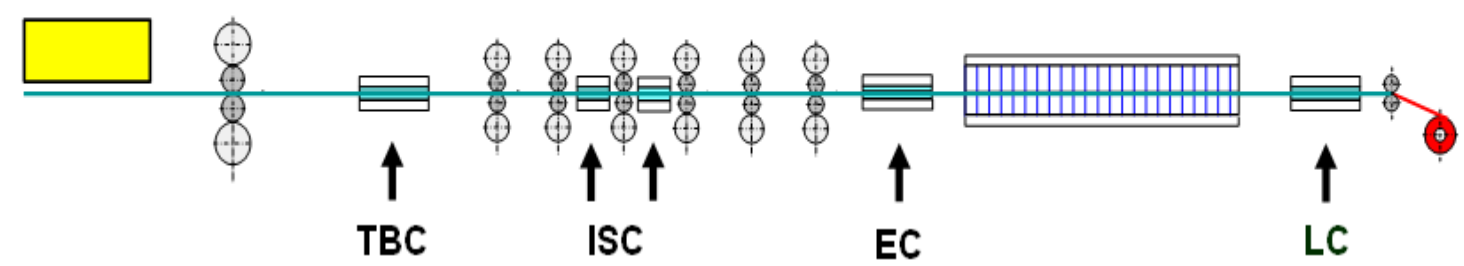

Figure 2: Layout of a hot strip mill with possible applications of the Power Cooling Technology

The Transfer Bar Cooling and Interstand Cooling location addresses throughput topics in view of thermomechanical rolling whereas the EC and LC location addresses the austenite-ferrite and the austenite-bainite/martensite transformation on the ROT with smallest possible wet zone length. In addition, using Power Cooling in the LC section provides the possibility to stably operate the cooling near the Leidenfrost region which is of increasing importance in view of DP and TRIP steels. Compared to laminar/intensive laminar cooling installations Power Cooling shows significantly higher water flows resulting in heat fluxes up to $5 \mathrm{MW} / \mathrm{m}^{2}$ and cooling rates close to the theoretical limit given by strip dimension, heat capacity and heat conductivity of the steel (see Table 1), while maintaining a wide control range for applicable flow rates to account for maximum metallurgical flexibility.

Table 1: Comparison of flow adjustment range and cooling rates reachable for different cooling technologies

\begin{tabular}{|l|c|c|c|}
\cline { 2 - 4 } \multicolumn{1}{c|}{} & $\begin{array}{c}\text { Laminar } \\
\text { Cooling }\end{array}$ & $\begin{array}{c}\text { Turbo }- \text { Laminar } \\
\text { Cooling }\end{array}$ & $\begin{array}{c}\text { Power } \\
\text { Cooling }\end{array}$ \\
\hline Adjustment range & $25-100 \%$ & $25-100 \%$ & $7-100 \%$ \\
\hline Cooling rate Struct. Steel $\mathrm{h}=6 \mathrm{~mm}$ & $\sim 45^{\circ} \mathrm{C} / \mathrm{s}$ & $\sim 64^{\circ} \mathrm{C} / \mathrm{s}$ & $\sim 175^{\circ} \mathrm{C} / \mathrm{s}$ \\
\hline Cooling rate Struct. Steel $\mathrm{h}=12.2 \mathrm{~mm}$ & $\sim 24^{\circ} \mathrm{C} / \mathrm{s}$ & $\sim 34^{\circ} \mathrm{C} / \mathrm{s}$ & $\sim 85^{\circ} \mathrm{C} / \mathrm{s}$ \\
\hline Cooling rate Struct. Steel $\mathrm{h}=25.4 \mathrm{~mm}$ & $\sim 11.5^{\circ} \mathrm{C} / \mathrm{s}$ & $\sim 17^{\circ} \mathrm{C} / \mathrm{s}$ & $\sim 40^{\circ} \mathrm{C} / \mathrm{s}$ \\
\hline
\end{tabular}

For existing installations Power Cooling technology gives the opportunity to significantly extend the product mix towards high strength grades and endorses the development of existing steel grades based on leaner chemistries significantly contributing to higher profit margins.

\section{Power Cooling at WISCO's HSM No. 2 in Wuhan, China}

With the installation of Primetal's Power Cooling immediately after the finishing mill, the Chinese steel producer WISCO entered successfully the AHSS market. The equipment was preassembled on site into units that could be lifted into position by the overhead crane after the existing equipment had been removed. So it was possible to minimize the total shutdown time to 15 days. To ensure proper drainage of the water on the top side, the roller table in the Power Cooling section was also exchanged. 
Technical Description of the Equipment. The Power Cooling unit after the finishing mill consists of 36 top and 36 bottom headers with a maximum total water flow of about 14,000 $\mathrm{m}^{3} / \mathrm{h}$. Each top header corresponds to one bottom header. The Power Cooling headers are equipped with solid jet nozzles to ensure maximum possible impact pressure. Table 2 shows the key figures of the Power Cooling System.

Table 2: Key Figures of WISCO Power Cooling

\begin{tabular}{|c|c|c|}
\hline Key figures & & \\
\hline No. of top and bottom headers & 36 & \\
\hline Max water flow rate at 3 bar & $14,000 \mathrm{~m}^{3} / \mathrm{h}$ & \multirow{2}{*}{$\begin{array}{l}\text { "Booster" } \\
\text { operation }\end{array}$} \\
\hline Pressure at nozzle & max. 3 bar & \\
\hline Water flow rate & $\sim 7,000 \mathrm{~m}^{3} / \mathrm{h}$ & \multirow{2}{*}{$\begin{array}{c}\text { "Laminar" } \\
\text { operation }\end{array}$} \\
\hline Pressure at nozzle & max. 0.8 bar (supply overhead tank) & \\
\hline Total length & $\sim 17 \mathrm{~m}$ & \\
\hline
\end{tabular}

Each pair of two top or two bottom Power Cooling headers features the following additional equipment:

- a pneumatically actuated on/off valve

- an electro - pneumatic flow control valve

- a manually operated valve

- a pressure transducer

For ventilation every top header is equipped with an automatic air venting valve. To calibrate each flow control valve, a flow measurement is integrated in a by-pass piping system. As mentioned above two headers are controlled by one pneumatic flow-control valve, which enables a wide control range of the flow rate. Because of the special design of the equipment, it is possible to reduce the flow rate for the Power Cooling headers to as low as $7 \%$ of the nominal flow.

The cooling section modernization included the installation of a new overhead tank. When extremely high cooling rates are required for some of the most critical products, it might happen that the overall flow rate required for cooling temporarily exceeds the supply to the tank. Since the tank is used as a buffer in this case, the total flow rate of the cooling water from the well to the tank could remain unchanged.

As for measurement a water free strip surface is needed, specially designed cross sprays are arranged between the gauge house and the first cooling header of the cooling section. Additional air sprays are installed at the same position to blow off the rest of the water and dry the surface.

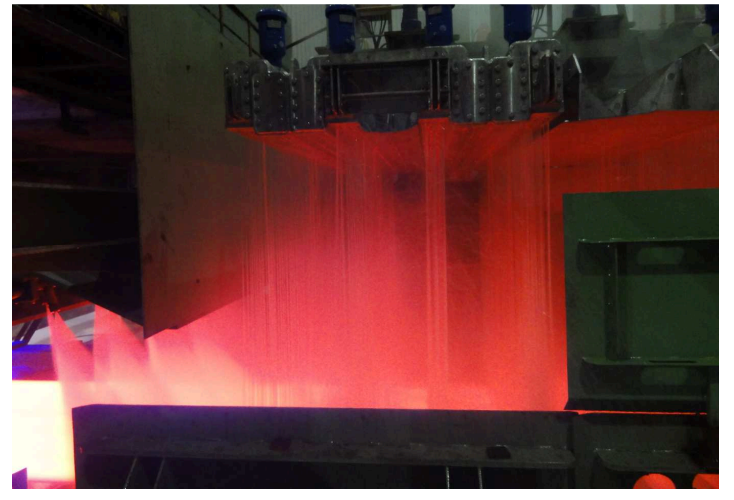

Figure 3: Power Cooling headers and Cross sprays in Operation (source: Primetals)

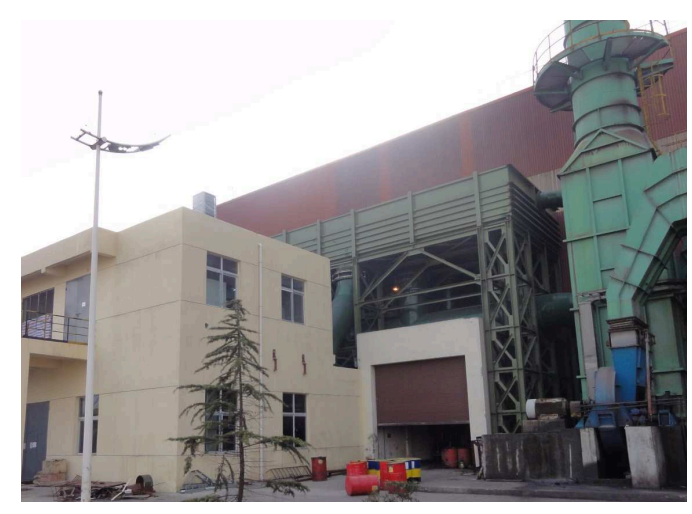

Figure 4: Newly installed overhead tank (source: Primetals)

Energy Savings due to Laminar Mode and Power Cooling Mode. To produce high-strength steel grades (AHSS), e.g. HSLA steel or as-hot-rolled multi-phase steel high cooling rates are necessary, so frequency-controlled pumps supply the headers with water. Conventional steel grades 
do not require such high cooling rates. In that case Power Cooling can be operated in laminar mode, which means the water is gravity-fed from the new overhead tank. These two modes can be realized by switching a valve in the supply line from the tank.

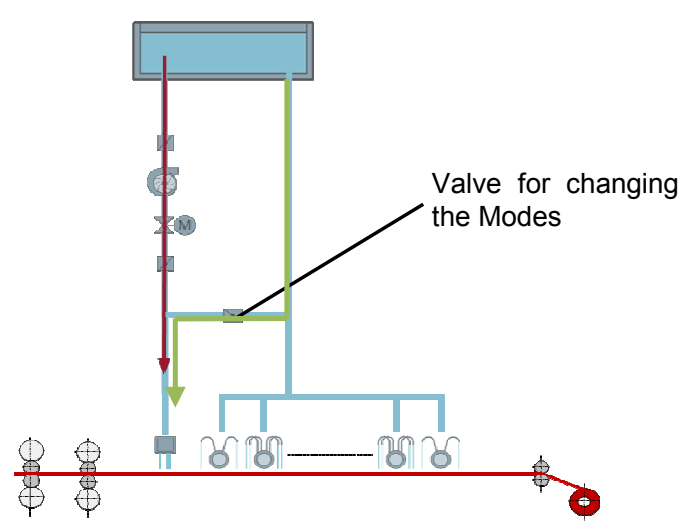

Figure 5: Switching of Modes (source: Primetals)

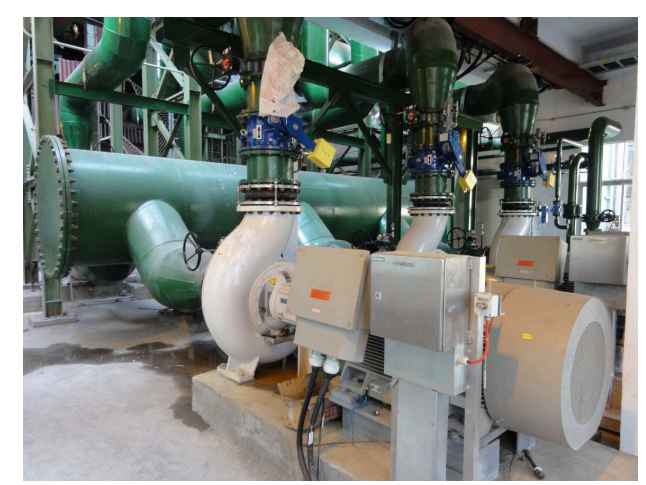

Figure 6: Frequency-controlled pumps (source: Primetals)

Comprehensive Temperature Control with Power Cooling. For improving the accuracy of temperature control a completely new automation strategy was developed. This new process automation allows excellent performance figures for finishing mill exit and coiling temperatures, although the increase of the water flow by the supplying water management system is up to 10 times faster than for hot strip mills with standard laminar cooling only.

\section{Late Cooling}

As-hot-rolled Multi-phase steel grades like DP, CP or TRIP steel require a two-step cooling strategy to obtain the requested microstructure. After cooling towards the ferrite nose a holding at an intermediate temperature is required to grow the appropriate amount of ferrite required in the final matrix. Depending on the steel grade intended, quenching below the martensite start temperature or rapid cooling into the bainite region is necessary after the holding zone. Using Power Cooling in the LC region has the benefit of quenching at shortest length possible as well as, due to the high energy of the water beam impinging on the strip surface to account for stable conditions in the otherwise unstable film boiling regime.

\section{Conclusion}

With the installation of a Power Cooling equipment high cooling rates are achievable and therefore superior microstructure, yield strength, tensile strength and toughness can be reached. The Power Cooling technology enables access to new product niches (e.g. Pipe Grades, DP) and thus allows producing new steel grades.

A Power Cooling system in front of the downcoiler allows achieving the required holding time for multiphase-steels, especially when the cooling section is not long enough. Also the cooling performance in the unstable film boiling regime increases a lot. 


\section{References}

[1] J. Maierl, J. Thoresson, E. Opitz, K. Weinzierl: High performance solutions for rolling of advanced high-strength steel grades in hot-strip mills. METEC 2015, 16.June - 20. June 2015

[2] J. Andorfer, G. Hribernig, A. Luger, A. Samoilov, P. Schwab, D. Auzinger and G. properties of hot-rolled strip with VAI-Q Strip, Revue de Métallurgie / Volume 97 / Issue 10 / October 2000, pp 1197-1204

[3] U. Lotter, H.-P. Schmitz, L. Zhang: Phys. J. IV France 120 (2004), S. 801

[4] source: voestalpine Grobblech $\mathrm{GmbH}$

[5] source: voestalpine Stahl GmbH 